\title{
Social acceptability of a marine protected area: The case of Reunion Island
}

\author{
Aurélie Thomassin $^{\mathrm{a}, *}$, Carole S. White ${ }^{\mathrm{b}, \mathrm{c}, * *}$, Selina S. Stead ${ }^{\mathrm{b}}$, Gilbert David ${ }^{\mathrm{a}}$ \\ ${ }^{a}$ Unité ESPACE S140-IRD, Campus universitaire de Moufia, BP 172, 97492 Sainte Clotilde Cedex, la Réunion, France \\ ${ }^{\mathrm{b}}$ School of Marine Science and Technology, Newcastle University, Newcastle upon Tyne NE1 7RU, UK \\ ${ }^{\mathrm{c}}$ Marine Resources Assessment Group (MRAG Ltd.), 18 Queen Street, London W1J 5PN, UK
}

\section{A R T I C L E I N F O}

\section{Article history:}

Available online 21 January 2010

\begin{abstract}
A B S T R A C T
This paper examines variations in social acceptability of a Marine Protected Area (MPA) prior to implementation. The influence of a number of factors, including socio-economic characteristics, perception of coral resources state of health and attitudes towards non-compliance with regulations are analysed. During May 2006, 640 questionnaires were distributed to school children around Reunion Island, Western Indian Ocean, for completion by their parents, following an informal educational activity made in school. From a $73 \%(n=469)$ response rate, results showed that $78 \%$ of participants were in favour of the MPA. Analysis further identified that those supportive of the MPA were generally from higher socio-professional categories, had a negative perception of the coral reef ecosystem's health and were not originally from Reunion. In contrast, locals (born in Reunion) from lower socio-professional categories or with no employment activity and having a positive perception of the health status of coral reefs offered no opinion on the MPA. Attitudes towards enforcement and compliance highlighted that SCUBA divers, fishers and jet skiers attributed a higher value to the protection of the coral reef environment through enforcement of MPA regulations than to their own use of the coral reef resource. When asked about the use of penalties to deter non-compliance, swimmers were awarded the lowest fines, followed by SCUBA divers, fishers then jet skiers being awarded the highest fines. Thus, the more severe the act of non-compliance by a resource user group was perceived to be, the more these users themselves disapproved of non-compliant behaviour and supported use of high penalties. The survey design through focusing on school children's parents, demonstrated a simple and cost-effective method for data collection while providing environmental education, which could be employed in similar case studies elsewhere.
\end{abstract}

(c) 2010 Elsevier Ltd. All rights reserved.

\section{Introduction}

\subsection{Marine protected areas and social science}

Marine Protected Areas (MPAs) or Marine Reserves (MRs) have become a popular tool for conserving biodiversity and managing extractive activities [1]. Targets have been set by Parties to the Convention on Biological Diversity (CBD) to protect $10 \%$ of the global marine environment by 2012 and recommendations have been made for $20-30 \%$ of major ecosystems to be fully protected in reserves by this date $[2,3]$. Coral reefs cover approximately $0.01 \%$ of the global marine area [4] and although an estimated $22.6 \%$ of coral reefs fall within some classification of legal protection [5], the

\footnotetext{
* Corresponding author: A. Thomassin, Tel.: +33 262 262588919; fax: +33262 262483353.

** Corresponding author: C.S. White, Tel.: +44 (0) 7779022014.

E-mail addresses: aurelie.thomassin@ird.fr (A. Thomassin), carole.s.white@ gmail.com (C.S. White).
}

extent to which coral reefs are being 'adequately managed' is disputed with some experts considering this to be less than 1 or $2 \%$ $[6,7]$. These figures indicate that the 2012 targets are unlikely to be met even for coral reefs - which may be considered to be better protected than other marine ecosystems [5].

Regardless of the 'quantity' of designated MPAs covering coral reefs, the 'quality' or effectiveness of existing MPAs is unknown as the assessment of 'management effectiveness' remains rather underdeveloped [8]. There is a need for monitoring methodologies to be developed to assess MPAs and to determine their effectiveness as management tools $[8,9]$. The objectives of MPAs are often multiple and include both social and ecological goals. However baseline studies, which allow future assessment to be carried out, tend to be focused on the collection of biological data rather than social data.

Inshore, coastal seas are often subject to an intensity and diversity of uses in which different resource users perceive their activity and its value differently, which can result in conflicts of interest [9]. In fact, conflict reduction and anticipation are often 
part of management objectives of MPAs. However, their creation can generate both internal (between use) and basic conflicts (between conservation and exploitation) [9-11]. Resource user conflicts, lack of public support and non-compliance have been at the root of MPA management failures [9,12,13] making the achievement of long-term management goals more costly and uncertain [12]. Despite the emphasized and recognised need for developing social science studies in marine conservation and management $[12,14]$, research in this field generally remains limited and accounts for only a small proportion of contributions to the literature on MPAs [15]. While further studies on perceptions of those directly or indirectly affected by MPAs have been stressed as crucial for assessing the degree of support and attitudes towards existing and future MPAs [16-20], a relatively small number of studies have done so [21].The lack of attention given to this research continues to hinder the success of MPAs as management tools [14,21-23].

\subsection{What is social acceptability?}

The notion of 'social acceptability' has become relatively common with respect to the implementation and assessment of many types of projects. Although a number of publications have dealt with social acceptability in subject areas including health or environmental risk [24-26] or forestry management [27-29], the social acceptability of protected areas remains a poorly explored area of research.

Because the notion has been employed in a variety of disciplines, its exact definition varies depending on the context in which it is used. For the purpose of this study, the definition of social acceptability was considered to be a measure of support towards a set of regulations, management tools or towards an organisation by an individual or a group of individuals based on geographic, social, economic and/or cultural criteria. As the social acceptability of a project is composed of the set of individual perceptions related to it, the use of the term 'social' was taken to mean 'a society' or 'a group of individuals'.

The assessment of social acceptability is complex and presents a number of challenges. These difficulties are inherent to the concept itself and an attempt is made to define and clarify the nature of this concept.

First, the concept is 'holistic' because its structure depends on multiple opinions, each opinion through the multiple perceptions of each individual on the topic in question, influenced by personal interests and to varying degrees public opinion. Therefore, researchers working on the social acceptability of health risks (for instance the risk of contracting a virus incurred by a sick patient receiving a blood transfusion) also consider social and ethical factors or the quest for equity in the assessment of acceptability [24].

Secondly, social acceptability is also a variable which can be used to determine the overall sentiment of society and enables its status to be evaluated without relation to the causes. Social acceptability can thus be regarded as holding a binary function. An individual can either choose to accept or reject, excluding the various degrees of acceptance or rejection which may lie somewhere in between. As a consequence, the only component which can be defined with relative certainty is that a distinct separation lies within social acceptability between the two opposed categories of opinion. The binary nature of social acceptability and nonacceptability is examined further in this paper. The opposite of social acceptability is social 'non-acceptability' or the rejection of a situation or a project.

The present study focuses on social acceptability of the MPA and is aimed at being used for MPA management purposes including the MPA itself as well as its surrounding areas. The non- acceptability of the MPA may result in a reduction of its efficiency related for example, to an increase in poaching or an increase in spending to ensure enforcement. Other concerns resulting from the non-acceptability of the MPA may include the generation of public protests and conflicts in surrounding areas.

\subsection{Categorising social acceptability}

Opinion can be broadly grouped into three categories: acceptance, rejection and indifference. Those with favourable opinions are considered to hold a position of acceptance and those with unfavourable opinions to hold a position of rejection. These opinions can be expressed overtly or covertly. While social acceptability can be identified, qualified and even quantified when it is in the overt form through the number of actions or speeches in the public arena, the covert form of social acceptability is discreet and remains in the private domain. Those that refuse to declare themselves as either in favour or opposed to the MPA are considered to hold a position of indifference (see Box 1 and Fig. 1).

Driving factors behind social acceptability may be linked to the underlying value or world view a person holds [30]. Examining these values further can help to measure and categorise acceptability particularly when this is expressed covertly.

Environmental economics employs the notion of 'use' and 'nonuse' values for attributing economic value to environmental goods and services [31,32]. Values of use are related to benefits resulting from consumption or non-consumption of an environmental resource. In the case of the Reunion MPA the use value can be considered as the collection of benefits derived from direct recreational uses (extractive or non-extractive) of the coral reef system (fishing, surf, SCUBA diving or swimming for example). The option value corresponds to the option of using a resource in the future and is based on the projected use value in the future. The intrinsic value is attributed to the coral reef system itself and is measured independently of any particular use. It is composed of the existence value, measured as Willingness to Pay for its preservation and the bequest value, measured as the value of preserving environmental assets for future generations.

The heritage value is defined in this paper as the association between the existence value, the option value and the bequest value. The heritage value drives a heritage 'view' which can be defined as one's willingness to protect a resource or a commodity

Box 1. : Favourable and unfavourable opinions: positions of acceptance and rejection.

\section{Illustration}

- Over rejection results in some form of public action against the MPA, which may be expressed verbally in the public domain or through public protests or noncompliant behaviour such as poaching.

- Covert rejection does not result in any form of action, or only through verbal expression restricted to the private domain.

- Indifference is always expressed covertly and is characterised by a lack of any form of overt expression.

- Overt acceptance results in some form of public action in favour of the MPA, mainly in daily newspapers, environmental NGO websites or newsletters.

- Covert acceptance does not result in any form of action, or only through verbal expression restricted to the private domain (Fig. 1) 


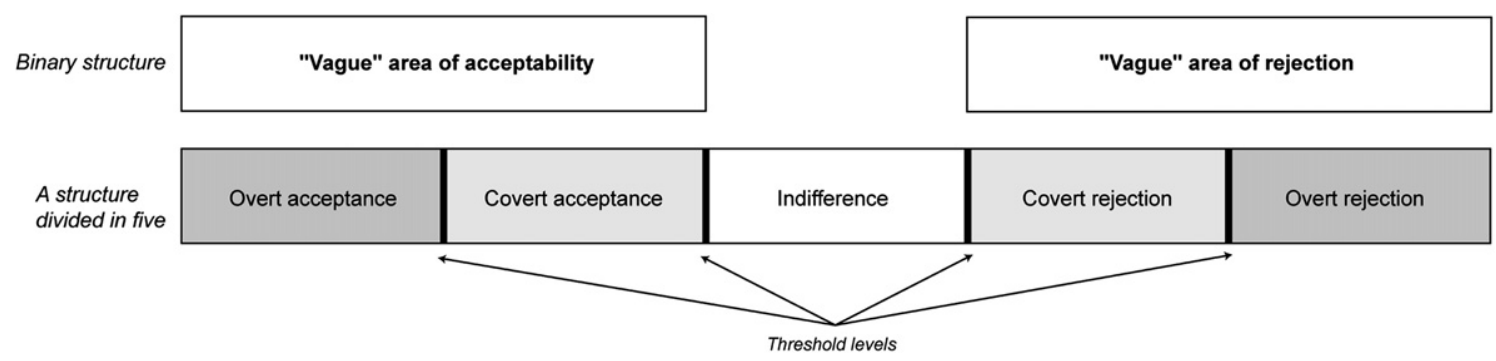

Fig. 1. Social acceptability: a structure that can be divided into five parts by threshold levels.

considered to be of great value for future generations. This differs from those with a 'notional view' of the MPA defined as one belonging to those that approve or even support the 'idea' of the MPA but in reality are not prepared to forgo their current use or enjoyment of the resource to ensure its sustainability. Individuals possessing a heritage view of the MPA are willing to compromise their use of the resource to ensure its sustainability whereas individuals with a notional view are not.

The objectives of this research were to develop a methodology to:

a) identify and understand contributing factors which influence social acceptability;

b) characterize groups of people who are likely to favour MPAs; and

c) assess variations in acceptability of individuals expressing favourable opinions towards MPAs.

\section{Methods}

\subsection{Assumptions and hypotheses tested}

The following research questions and assumptions are described below:

1) Geographical location of residence in relation to the MPA: Does social acceptability vary with the time-distance criterion? It is assumed that local residents with the shortest travel time to the MPA are more likely to be direct users or, at least, more frequent users than inhabitants of areas with longer travel times to the MPA (Table 1). Thus it was hypothesized that respondents in relative close proximity to the MPA are more likely to be affected by new regulations associated with the MPA and consequently more likely to reject it. Proximity can be a factor which influences public support towards MPAs [33].

Table 1

Distance between schools, proximity to the MPA and questionnaires collected.

\begin{tabular}{lccl}
\hline Site & $\begin{array}{l}\text { Number of } \\
\text { questionnaires }\end{array}$ & $\begin{array}{l}\text { Time distance } \\
\text { in minutes }\end{array}$ & Group \\
\hline St Gilles centre & 35 & 0 & West coastal \\
Hermitage & 43 & 0 & West coastal \\
La Saline less bains & 40 & 0 & West coastal \\
Etang-Salé ville & 27 & 5 & West coastal \\
St Pierre centre & 42 & 24 & South \\
Terre Sainte & 17 & 26 & South \\
Tan Rouge & 24 & 36 & West highlands \\
Trois Bassins centre & 35 & 35 & West highlands \\
Chaloupe St Leu & 26 & 40 & West highlands \\
St Benoit centre & 59 & 76 & North-East \\
St André centre & 17 & 70 & North-East \\
St Denis centre & 41 & 52 & North-East \\
Total & $\mathbf{4 0 6}$ & & \\
\hline
\end{tabular}

2) Resource use: Does social acceptability vary according to the frequency of resource use?

Following the assumption that resource users were more likely to be affected by new regulations associated with the MPA, the hypothesis was that respondents involved in a greater number or range of 'marine/beach-related' activities were more likely to be opposed to the MPA. Secondly, that the type of activity (whether observational or extractive) may influence social acceptability differently with those involved in extractive activities being more likely to reject the MPA. Differences in perceptions have been found to influence perceptions and support towards MPAs [18].

3) Perception of the marine environment: Does social acceptability vary according to the perception of health status of coastal ecosystems?

Following the assumption that the perception held by someone on the state of health of an ecosystem will influence their behaviour and level of support towards the MPA, the hypothesis developed that respondents perceiving the coral reef ecosystem to be unhealthy were more likely to support the MPA. The perception of ecosystem health and its resilience has been found to affect the extent of depreciative behaviours [30] and thus may influence acceptability of an MPA and regulations.

4) How do socio-economic parameters influence social acceptability?

Many social science studies have shown that socio-economic characteristics play a significant role in shaping behaviours and perceptions [34-37]. Social acceptability was therefore analysed in relation to origin and employment status. No hypothesis was formed but it was expected that these would contribute in some way to opinions on the MPA.

5) How can the underlying values towards marine protection be used to define a scale of social acceptability?

Perceptions and social acceptability are difficult to measure particularly as they can be expressed covertly or overtly and are constantly subject to external influences and to change. Assuming that the value awarded to the MPA is also related to a cost (lost opportunities of resource use due to regulations), the willingness to accept the implementation penalty fees for non-compliance was taken to be an indicator of those holding a 'heritage view' while those that were not willing to accept such penalties did not. Instead, these were considered to hold a 'notional view' of the MPA. Secondly, it was assumed that an individual with a 'heritage view' of the MPA was more likely to hold a long-term favourable opinion towards the MPA than one with a 'notional view'. These different 'views' were used to evaluate differences in favourable opinions towards the MPA 
Variations in the level of acceptance and rejection of MPAs among individuals are examined in this paper using the case study of the Reunion Island Natural Marine Reserve. In particular, the group categorised as holding a favourable opinions is further examined. A novel and cost-effective method is presented for assessment of social acceptability of MPAs, which is widely applicable to other related topics and study areas.

\subsection{Study area: the Reunion Island Natural Marine Reserve}

Reunion Island is an Overseas Department of France, located in the Western Indian Ocean. Over 82\% of Reunion's population (approx. 784, 000 in 2006) is concentrated on the coast with the west being subject to the highest urbanisation holding a population density three to four times higher than average per hectare [38,39]. This coincides directly with the islands' coral reefs which are situated in the west (Fig. 2). Although Reunion's fringing reefs are geologically underdeveloped $\left(12 \mathrm{~km}^{2}\right)$ and characterised by relatively low fish diversity (885 species) in comparison to other reef communities of the Indian Ocean [40] their social and economic value is high.

Tourism, and fisheries on the side of the island with the Marine Reserve, are linked to the high productivity and coastal protection provided by the reef system resulting in white sand beaches and sheltered, shallow conditions for fishing in the "lagoon", contrasting with black sand of volcanic origin and dangerous sea conditions in the east [41]. These provide nurseries for many fish species $[42,43]$. However, they are under increasing environmental [44] and human pressure particularly due to their proximity to the coast. Coral degradation has been observed since the 1970s with coral mass mortality first noted in 1983 and a reduction of $73 \%$ live coral cover between 1978 and 1994 [42]. Effects of excessive eutrophication from domestic and industrial pollution have been linked to coral degradation $[45,46]$. High fish mortality was linked to bacterial pathogens in the water in 2002 as well as over-exploitation of reef fisheries resulting in a decline of fish trophic levels $[46,47]$. With population predicted to reach one million inhabitants by 2030 , there is an urgent need for sustainable coastal planning and development. All of the reefs are currently protected and regulated to some extent, mostly through fishery regulations since
1992 although these are largely un-enforced and recorded offences are not prosecuted [48]. An MPA was established by ministerial decree, signed in Paris on the 21st of February 2007 with the status of "Natural Marine Reserve". It covers all the reef areas from Cap La Houssaye in Saint-Paul to Etang-Salé (Fig. 2). The MPA is multi-use allowing both extractive and non-extractive activities to co-exist through zonation with strict resource protection no-take zones (NTZ).

This study was conducted in the context of a socio-economic baseline assessment commissioned by the regional Department for the Environment (DIREN) undertaken by the Institute for Research and Development (IRD) in 2006 prior to the establishment of the MPA.

\section{Survey methodology}

\subsection{Development of questionnaire and approach to data collection}

Data was collected via questionnaires through the medium of primary schools using the pupils' parents as the sample for the study. The questions asked and the rationale for the data collection approach is described and followed by Strengths, Weaknesses, Opportunities and Threats (SWOT) analysis (Table 2).

The questionnaire included 27 closed and 3 open questions as well as a map of the MPA project. The questions used for the research objectives of this paper included: opinion and awareness of the MPA, two questions on the frequency of resource use (frequently: daily, often: weekly, occasionally: monthly, rarely: yearly and never) and type of marine/beach-related activities practiced (swimming, diving, fishing, jet-skiing), three questions on the perception of the marine environment and change (abundance of fish, aesthetic appearance and overall coral resources state of health). The responses to these questions were used to evaluate the hypotheses posed as posed above.

Personal socio-economic information was also collected on gender, country of birth, age, employment, residency area. Employment responses were grouped into four socio-professional categories (SPCs) reflecting estimated income, referred to in the text as: "High SPC" (civil servants, managerial and freelance positions), "Middle SPC" (skilled workers, private sector or public

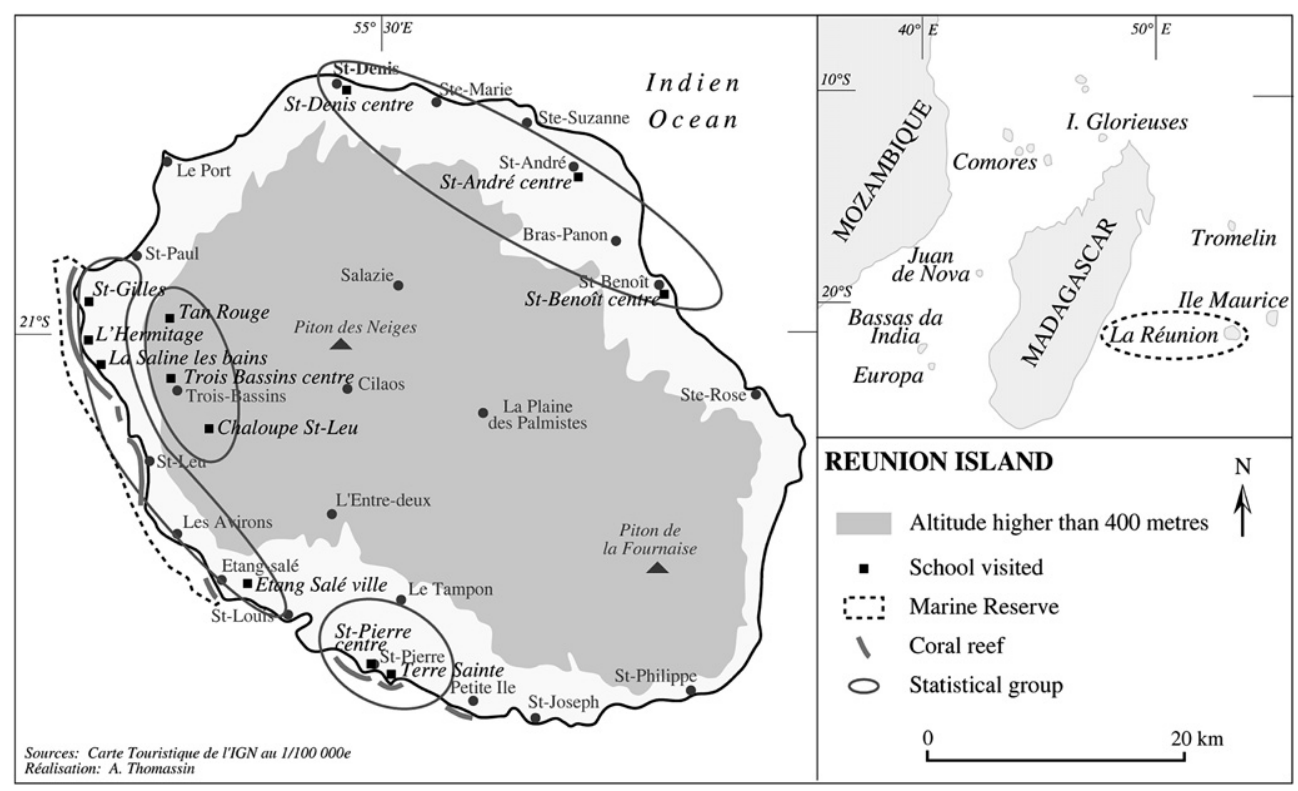

Fig. 2. Reunion Island localisation and spatial distribution of the surveyed schools. 
Table 2

Analysis of strengths, weaknesses, opportunities and threats of the method.

\begin{tabular}{|c|c|}
\hline Strengths & Weaknesses \\
\hline $\begin{array}{l}\text { - Easy to replicate for managers } \\
\text { - A high response rate } \\
\text { - Time and cost effective: low time input from the research team } \\
\text { - Limited bias which can result from the influence of researcher on the respondent } \\
\text { - Sample representative of socio-economic characteristics associated with the area }\end{array}$ & $\begin{array}{l}\text { - Low number of young and single or old/retired individuals } \\
\text { - Illiteracy of some parents. Potential for random answers } \\
\text { to be selected }\end{array}$ \\
\hline $\begin{array}{l}\text { Opportunities } \\
\text { - Assessment of school parent's views which may contribute to influence the children's } \\
\text { views and considered as crucial for future change } \\
\text { - Raise awareness and provide environmental education on terrestrial/marine issues in schools }\end{array}$ & $\begin{array}{l}\text { Threats } \\
\text { - Influence from the students on their parents }\end{array}$ \\
\hline
\end{tabular}

services), "Low SPC" (unskilled workers and general employees), and "No activity" (unemployed, students, pensioners, house wives). Origins were assessed in terms of birth place and used as an indicator of culture. These were categorised as (1) "Reunion Island" (2) "Mainland France" (3) "Abroad" (including all other countries in Europe and the rest of the world).

Two questions were used to assess attitudes towards enforcement and compliance. Respondents were asked to rank perceived severity of non-compliance (presence in the sanctuary zone) of different resource users. They were then asked to imagine that they were a judge and were required to allocate a fine to first and second time offenders. Six responses were possible: no action, an official warning or a fine of $10 €, 50 €, 150 €$ or $1000 €$. Based on these responses, opinions on the MPA (social acceptability) were assessed on a finer scale resulting in a gradation between those holding a 'notional view' or a 'heritage view' of the coral reef ecosystem.

An educational activity which had no direct link to the topic of the questionnaire was presented in each class room prior to the distribution of the questionnaire. It included a demonstration model explaining the process of erosion, water run-off, the links between the terrestrial environment, the catchment area and the coral reef ecosystem, particularly the effects of terrestrial-based pollution (agricultural or domestic) on coral reefs. The activity and questionnaire were tested on school groups and 76 respondents by the IRD and CIRAD (Centre de Cooperation Internationale en Recherche Agronomique pour le Développement) at a Science Fair in St Denis, Reunion in November 2005. The activity generated a great deal of interest both from school children and their teachers with many of these requesting visits from the team to their schools. A first version of the questionnaire was piloted at a primary school in St Paul and then further revised.

The decision to collect data in this way presented several advantages. Firstly, as local residents are obliged to send their children to the nearest primary state school, the data collected from each school could be linked to residency in the immediate local area. This also enabled the research team to obtain a representative sample in terms of the socio-economic characteristics associated with the residents of each area by selectively targeting a variety of areas.

\subsection{Fieldwork and sampling strategy}

Before undertaking data collection, the research team considered what the 'relevant' sample size would be necessary for the purposes of this particular study. The stakeholders needed to be identified and included in the sample whether they were likely to be directly or indirectly affected by the MPA. In similar perception studies, which often deal with rural areas, the primary stakeholders are usually identified as the «local community". In these cases, the effects of a project can be clearly identified as localised on a particular population. The primary stakeholders are also commonly defined in relation to their proximity to the MPA, based on the assumption that those living close by are more likely to be resource users. However, due to the relatively urbanised and insular nature of Reunion Island, the identification of the 'relevant' sample is not quite as clear. As the population has become increasingly mobile, with most families having access to a car, resource users do not necessarily need to live within immediate proximity of the MPA. Therefore, the research team concluded that the entire population of Reunion Island could potentially be defined as a stakeholder. It was therefore concluded that the sample should encompass as wide a geographical area as possible using a sample size to represent the overall sentiment on the island to assess what is defined here as 'public opinion'.

Field work was conducted by a team of two researchers who visited 30 classrooms in twelve pre-selected state primary schools between the 2nd and 26th of May 2006, distributing a total of 640 questionnaires. Following the interactive educational activity, questionnaires were handed to each child, clearly explaining this should be filled in by a parent or other adult in their household. Educational booklets and posters (donated by the Association for the Marine Park) for each child were handed to the teacher with a stamped envelope and instructions of where to send the completed questionnaires. An extra incentive to complete the questionnaire was that these would be entered into a prize draw of a school trip to the Aquarium of Reunion. This motivated both the teachers and pupils to ask their parents to spare 5-10 min to complete the questionnaire.

The sample was stratified geographically into four geographic location types referred to in this paper as: "North-East", "South", "West Coast" and "West Highland" from each of which a relatively even sample was sought.

A time-distance selection criterion was used to collect perceptions of residents at different distances from the future MPA in order to assess the overall public perception and also identify differences between individuals living in different areas. Travel time was chosen as the most appropriate means of categorising locations as the quality of infrastructure, the rugged terrain, the disparity of fast roads and traffic congestion would limit travel rather than actual distance. Approximate travel time from each location to coast was calculated by the research team using local knowledge, bus timetables and detailed maps (Table 1 ). In addition to the difference in travel time, the West Coastal group and the West Highlands group, (Fig. 2), although both situated in the west are socio-economically very distinct. West Highlands residents are mainly of local origin (born in Reunion), from working class to middle social classes whereas the West Coast has a high concentration of residents that have immigrated to Reunion from mainland France or elsewhere abroad and belong to the wealthiest social classes on the island.

The research team visited schools which were grouped into the four geographic categories using the time-distance criterion: The West Coastal group (between 0 and $15 \mathrm{~min}$ ), the South group 
(between 15 and $30 \mathrm{~min}$ ), the West Highlands group (between 30 and $50 \mathrm{~min}$ ) and the North-East group (more than $50 \mathrm{~min}$ ).

\subsection{SWOT analysis}

Bearing in mind the objective to conduct a baseline assessment, for which this study was commissioned, the method needed to be easily replicated both methodologically and economically. The choice of primary schools as a medium for collecting data was considered to be appropriate particularly in light of the MPA managers' terms of reference to conduct awareness-raising and environmental education activities in schools.

This method allowed surveys to be easily replicated with a minimal amount of extra time from the MPA management staff, important for when the MPA impacts are assessed in future. The method was also extremely time and cost-effective requiring low time input from a small research team. The questionnaires were distributed to parents via their children, responding to it independently at home and then collected by their children and transmitted to the researchers by the teachers. This also limited the bias which can occur in social surveys from the unavoidable influence of researcher on the respondents' behaviour with answers resulting from the human interaction between the two.

The method used resulted in a particularly high response rate: From a total of 640 questionnaires distributed, 469 were returned at a response rate of $73 \%$ and from these 406 could be used with $13 \%$ of incomplete questionnaires (Table 2). This method also enabled the attainment of a representative sample in terms of socioeconomic characteristics of each area and a representative sample size geographically.

In addition to collecting data, this method could also raise awareness and provide environmental education on terrestrial/ marine issues in schools. The focus on parents' perceptions is important as they were likely to significantly influence children's' awareness and perceptions which is often considered crucial for future change [37].

A potential weakness in this method is that it included a low number of young and single ( $4 \%$ aged between 18 and 25 years old), or old/retired individuals ( $<1 \%$ over 60 years old). Illiteracy among parents presented a challenge to the survey, particularly in certain schools visited. This may have caused a bias through the possibility of these respondents filling in the wrong answers or filling these in randomly.

A Spearman's Rank Correlation and Pearson's Chi-squared tests were conducted to examine the relationship between four significant variables with social acceptability, and a Factor Analysis (FA)

Table 3

Summary of socio-economic characteristics of the sample.

\begin{tabular}{lrr}
\hline & Sample & $\%$ \\
\hline Gender & 136 & 38 \\
Male & 218 & 62 \\
Female & 354 & 100 \\
Total & & \\
Origin & 32 & 20 \\
Reunion Island & 113 & 69 \\
Mainland France & 18 & 11 \\
Abroad & 163 & 100 \\
Total & & \\
Employment & 113 & 33 \\
Higher level & 38 & 11 \\
Middle level & 100 & 29 \\
Low level & 96 & 28 \\
No activity & 347 & 100 \\
Total & &
\end{tabular}

Table 4

Summary of uses and perceptions characteristics of the sample.

\begin{tabular}{|c|c|c|}
\hline & Sample & $\%$ \\
\hline \multicolumn{3}{|l|}{ How frequently do you visit the MPA area? } \\
\hline Frequently & 21 & 5 \\
\hline Very often (at least once per week) & 138 & 34 \\
\hline Often (at least once per month) & 179 & 44 \\
\hline Occasionally (at least once a year) & 64 & 16 \\
\hline Never & 4 & 1 \\
\hline \multicolumn{3}{|l|}{ Which activities do you practice when you go to the sea side? } \\
\hline No activity & 216 & 53 \\
\hline Extractive activities (spear fishing and traditional fishing) & 31 & 8 \\
\hline Observational activities (diving and snorkelling) & 74 & 18 \\
\hline Water sports (sailing, jet ski, surfing, kite-surfing...) & 8 & 2 \\
\hline Multiple activity types (two or more) & 77 & 19 \\
\hline \multicolumn{3}{|c|}{ What do you think of the current state of health of coral ressources? } \\
\hline Good & 23 & 6 \\
\hline Quiet good & 161 & 40 \\
\hline Quiet bad & 181 & 45 \\
\hline Bad & 40 & 10 \\
\hline \multicolumn{3}{|c|}{ From an aesthetic point of view, do you think the submarine environment has changed? } \\
\hline Yes, it has become more beautiful & 45 & 11 \\
\hline No, it has not changed & 40 & 10 \\
\hline Yes, it has become less beautiful & 208 & 51 \\
\hline I don't look underwater & 113 & 28 \\
\hline \multicolumn{3}{|c|}{ Since you've been going to the beach, doyou think the number of fish in the lagoon has... } \\
\hline Increased a lot & 5 & 1 \\
\hline Increased a little & 20 & 5 \\
\hline Has not changed & 22 & 5 \\
\hline Decreased a little & 101 & 25 \\
\hline Decreased a lot & 143 & 36 \\
\hline Don't know & 111 & 28 \\
\hline
\end{tabular}

was used to further examine the relationship between the factors identified as contributing to social acceptability.

\section{Results and analysis}

\subsection{Exploring social acceptability}

The results presented in this section describe data collected on perception of ecosystem health, recreational resource use, opinions towards the MPA and regulations as well as the socio-economic characteristics of the respondents.

The analysis of results was divided into three parts following the three research objectives of the study: understanding the contributing factors which influence social acceptability, characterizing the groups of people who were likely to be in favour of the MPA, assessing variations with those holding favourable opinions and finding sub-positions as referred in Fig. 2.

The majority of respondents to the questionnaire were female (62\%) and were born in mainland France (69\%). The sample represented a relatively even distribution of different socio-professional categories (Table 3 ).

The majority of the sample visited the MPA area 'often' on a monthly basis (44\%) or more frequently, on a daily or weekly basis (39\%). Most of the respondents did not practice any marine-related recreational activities (53\%). Of those that did, observational activities such as SCUBA diving or snorkelling (18\%) were most

Table 5

Summary of opinions towards the MPA

\begin{tabular}{lcr}
\hline & Sample & $\%$ \\
\hline What is your opinion concerning the creation of MPA in Reunion Island? & \\
In favour & 318 & 78 \\
Undecided & 39 & 10 \\
Opposed & 3 & 1 \\
Without opinion & 38 & 9 \\
No answer & 8 & 2 \\
Total & 406 & 100 \\
\hline
\end{tabular}


Table 6

Results from one way Chi-squared tests between social acceptability and variable (DF = Degree of freedom and p measure the risk to reject the null hypothesis).

\begin{tabular}{|c|c|c|c|c|c|c|c|c|c|}
\hline & \multirow{2}{*}{$\frac{\text { Geography }}{\text { Time distance }}$} & \multicolumn{2}{|c|}{ Marine activities } & \multicolumn{3}{|c|}{ Perceptions of marine environment } & \multicolumn{3}{|c|}{ Socio-economical parameters } \\
\hline & & FBV & BRA & CRSH & $\mathrm{AA}$ & FA & Gender & Origin & Employment \\
\hline SA & $\begin{array}{l}\chi^{2}=10.49 \\
D F=6 \\
p=0.109\end{array}$ & $\begin{array}{l}\chi^{2}=2.73 \\
D F=8 \\
p=0.950\end{array}$ & $\begin{array}{l}\chi^{2}=4.98 \\
\mathrm{DF}=8 \\
p=0.76\end{array}$ & $\begin{array}{l}\chi^{2}=17.85 \\
D F=9 \\
p=0.037\end{array}$ & $\begin{array}{l}\chi^{2}=2207 \\
D F=6 \\
p=0.9\end{array}$ & $\begin{array}{l}\chi^{2}=15.14 \\
D F=12 \\
p=0.23\end{array}$ & $\begin{array}{l}\chi^{2}=2.52 \\
D F=3 \\
p=0.471\end{array}$ & $\begin{array}{l}\chi^{2}=18.87 \\
D F=6 \\
p=0.004\end{array}$ & $\begin{array}{l}\chi^{2}=33.47 \\
D F=9 \\
p=0.0001\end{array}$ \\
\hline
\end{tabular}

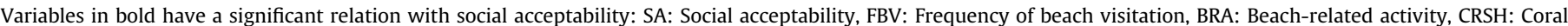
resource state of health, AA: Aesthetic appearance of submarine landscape, FA: Fish abundance.

popular, followed by extractive activities such as fishing (8\%), then water sports, although $19 \%$ were involved in a combination of these. Most perceived that the aesthetic appearance of the submarine environment had changed for the worse, although almost a third claimed never to look underwater. Fish abundance was perceived to be decreasing according to $61 \%$ of respondents, although almost a third of them did not express an opinion. Despite this, the overall status of the ecosystem was perceived bad or very bad by $55 \%$ of the sample (Table 4 ).

Social acceptability was measured indirectly through the question: What is your opinion concerning the creation of an MPA in Reunion Island? (Table 5). The analysis used all the expressed responses ( $n=398$ ) to assess opinions towards the MPA.

The majority of responses (78\%) were found to be in favour of the MPA with only a small percentage (1\%) expressing that they were not (Table 5). Noteworthy is that $21 \%$ of respondents had 'no opinion' or were 'undecided' or did not answer the question posed. A majority (82\%) of those stating 'no opinion' were unaware of plans for an MPA. This high proportion is significantly greater than the level of awareness among the total population sampled (39\%). The lack of information on the MPA, prior to implementation, could explain the high rate of ignorance.

\subsection{Understanding social acceptability and influencing factors}

Pearson's chi-squared test (Table 6) and Spearman's Rank Correlation (Table 7) were used to assess which factors contributed to social acceptability and to test the hypotheses described above.

Frequency of visits to the MPA area and involvement in marine and/or beach-related activities were found not to influence social acceptability (Table 6). Thus, the second hypothesis (those involved in extractive activities would hold more unfavourable opinions) was therefore rejected.

Travel time to the MPA was weakly correlated to social acceptability if a $10 \%$ error margin was accepted. Although not statistically significant, this may be appropriate in the case of qualitative social science statistics given the need to take account of subjectivity when determining variation between individual responses to the same questions and considering the relatively large sample size ( $n=398$ ). However, the first hypothesis (those living in close proximity to the MPA would hold more unfavourable opinions to it) could not be approved at this stage and was thus rejected.

Negative perceptions of the coral resources health status (CRHS) was found to contribute to a favourable opinion towards the MPA

Table 7

Spearman's Rank Correlation (rs) between significant variables and MPA social acceptability.

\begin{tabular}{lllll}
\hline & Time distance & CRSH & Origin & Employment \\
\hline SA & rs $=-0.063^{*}$ & rs $=-0.153^{* *}$ & rs $=-0.166^{* * *}$ & $r=0.231^{* * * *}$ \\
\hline${ }^{*}$ Significant with $p=0,2,{ }^{* *}$ Significant with $p=0,01,{ }^{* * *}$ Significant with $p=0.001$, \\
${ }^{* * * *}$ Significant with $p=0,00001$. \\
Rs: Spearman's rank, SA: Social Acceptability, CRSH: Coral resource state of health
\end{tabular}

while positive perceptions of the CRHS were correlated with unfavourable opinions towards it. Thus, the third hypothesis (those that perceived the coral reef ecosystem to be unhealthy would hold more favourable opinions) was approved.

A Spearman's Rank Correlation was conducted to examine the relationship between four significant variables with social acceptability (Table 7). This revealed that employment category $\left(r^{2}=0.053\right)$, origin $\left(r^{2}=0.028\right)$ and perception of the ecosystem's state of health $\left(r^{2}=0.023\right)$ were each weakly correlated to social acceptability (individually accounting for $5.3 \%, 2.8 \%, 2.3 \%$, respectively. Individuals born on Reunion Island tended to have unfavourable opinions towards the MPA as did those categorised in the lowest employment categories (including the unemployed and low paid employees). Thus, socio-economic parameters (origin and employment) contribute to the social acceptability of the MPA in Reunion Island.

\subsection{Characterisation and distribution of social acceptability}

Results of the Factor Analysis show that although proximity to the MPA was only weakly correlated to social acceptability, it was also included in the FA (see Fig. 3).

The $\mathrm{F} 1$ axis value, of close to $71 \%$, suggests that the variance detected in the data and two population types can be characterised:

- One population type is associated with a relatively negative perception of the CRSH and a favourable opinion towards the MPA. This group is characterised by a relatively large proportion originating outside (country of birth) of Reunion Island (contributing $19.7 \%$ to the F1), belonging to higher socioprofessional categories (contributing 13.7\% to F1) and living on the West Coast (contributing 12.5\% to F1).

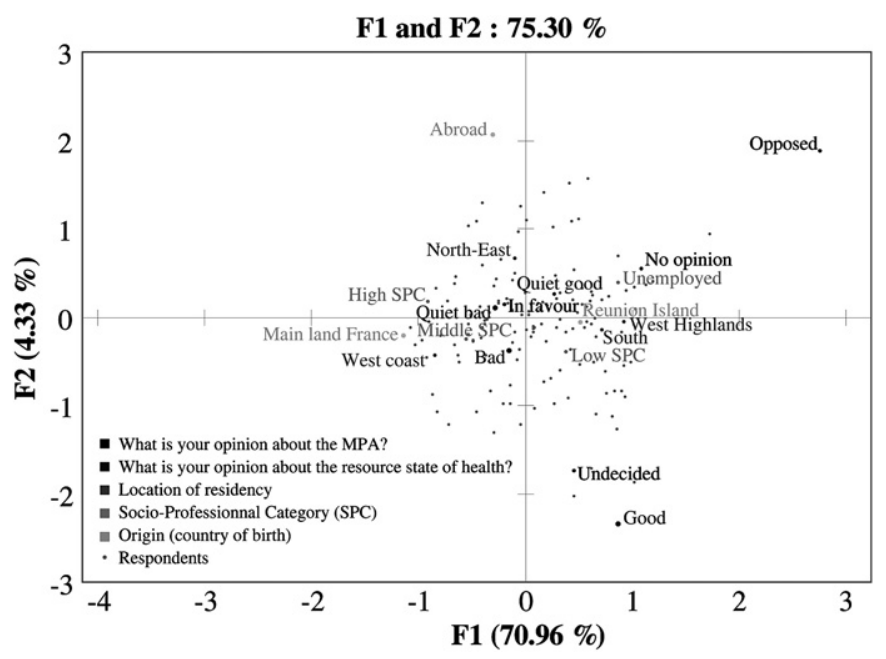

Fig. 3. Factor analysis between opinion of the MPA and the four significant variables. 
Table 8

Choices made by each resource user type towards similar resource users exhibiting non-compliant behaviour.

\begin{tabular}{|c|c|c|c|c|c|c|}
\hline User/Offender & $\begin{array}{l}\text { Swimmer/Swimmer } \\
(n=263)\end{array}$ & $\begin{array}{l}\text { Fisherman/Fisherman } \\
(n=37)\end{array}$ & $\begin{array}{l}\text { Diver/Diver } \\
(n=128)\end{array}$ & $\begin{array}{l}\text { Jet ski/Jet ski } \\
(n=15)\end{array}$ & $\begin{array}{l}\text { No uses/All user types } \\
(n=157)\end{array}$ & Total $^{\mathrm{a}}(n=605)$ \\
\hline Notional value & $25.90 \%$ & $10.80 \%$ & $8.70 \%$ & $6.70 \%$ & $9.20 \%$ & $13.30 \%$ \\
\hline Low heritage value & $52.50 \%$ & $16.20 \%$ & $27.00 \%$ & $6.70 \%$ & $24.20 \%$ & $31.00 \%$ \\
\hline High heritage value & $21.70 \%$ & $73.00 \%$ & $64.30 \%$ & $86.70 \%$ & $66.60 \%$ & $55.80 \%$ \\
\hline Total & $100 \%$ & $100 \%$ & $100 \%$ & $100 \%$ & $100 \%$ & $100 \%$ \\
\hline
\end{tabular}

a One person can practice several activities.

- The other population type is associated with having a relatively good perception of the CRSH and an absence of opinion about the MPA. This population type is characterised by a relatively large proportion originating from Reunion Island (contributing $10.6 \%$ to F1) belonging to lower socio-professional categories or with no employment activity (contributing 10.9\% to F1) and living in the West Highlands (contributing 9.7\% to F1) or in the South (contributing $4 \%$ to F1).

\subsection{Using values to define a scale of acceptability}

Although the basic analysis of responses to the question "What is your opinion concerning the creation of an MPA in Reunion Island?" allowed social acceptability to be quantified indirectly, further analyses showed that it was difficult to demonstrate a strong relationship between social acceptability and the hypothesized contributing factors. This may partly be explained by the relatively high acceptance level (78\%) in the sample surveyed which made distinguishing the factors contributing to the remaining $22 \%$ more difficult.

In order to go beyond categorising opinions into the various positions discussed in Box 1, to understand and measure the degree of social acceptability, the underlying reasons on which opinions are based were examined further, focusing only favourable opinions. In an attempt to distinguish levels of support towards the MPA (within the group declaring themselves 'in favour' of it), the value awarded to marine protection was analysed based on the penalty fees awarded to different resource users. In order to remove the bias associated with judging other resource uses, the responses were analysed against the activities each respondent had themselves stated involvement in. The assumption was that the higher the penalty fee selected as an appropriate fine by an individual for non-compliant behaviour by another similar type of user, the higher the non-use existence value was they attributed to the MPA compared to the use value of being able to carry out that activity them self). Choices made by each resource user type towards other resource users of the same type exhibiting non-compliant behaviour are summarised in Table 8.

The following typologies were used:

- High heritage view: Those that attribute a lower value to their activities (use value) than the value attributed to the coral reef

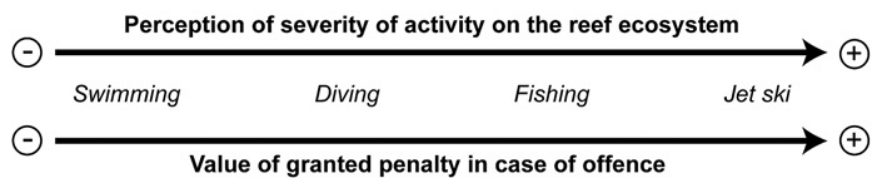

Fig. 4. Gradient of perceived severity of recreational activities on the coral reef ecosystem and the penalty awarded by other resource users in case of non-compliant behaviour. ecosystem itself (non-use value). This group approves of awarding relatively severe penalties (over $€ 100$ ) to offenders or to at least increase the penalty (to over $€ 100$ ) for second time offenders.

- Low heritage view: Those that attribute an equal value to their own activities (use value) than to the value attributed to the coral reef ecosystem itself (non-use value). This group approves of the use of financial penalties for non-compliant behaviour but select relatively low fines (maximum of $€ 50$ ).

- Notional view: Those that attribute a higher value to their own activities (use values) than the value attributed to the coral reef ecosystem itself (non-use value). This group does not approve of using any level of fine in the case of non-compliant behaviour.

With the exception of swimmers, all resource user types attributed a higher value on the need to protect the coral reef (through enforcement) than on their own activity. However, when the penalty choices are analysed it seems all respondents (regardless of the activity they are involved in) awarded similar penalty levels on non-compliant resource users. Swimmers present in the sanctuary zone received the lowest fines ( $€ 4$ on average for the first offence and $€ 28$ for the second), followed by SCUBA divers ( $€ 33$ on average for the first offence and $€ 109$ for the second), followed by fishermen ( $€ 40$ on average for the first offence and $€ 117$ for the second) and jet skiers ( $€ 123$ on average for the first offence and $€ 196$ for the second).

This increasing order of penalty level attributed to each user type follows the same order as the perceived severity of noncompliance by these user types (Fig. 4). In other words, the more severe the act of non-compliance by a particular type of user was perceived to be overall, the more these users themselves disapproved of non-compliant behaviour and supported the use of high penalties.

Based on the total proportions measured in Table 9, social acceptability can be assessed on a finer scale resulting in a gradation of the level of acceptability. Three degrees of acceptance can be distinguished, depending on the ratio of use value/non-use value, within the assessed social acceptability.

A majority $(87 \%, n=276)$ of people in favour of the MPA $(n=318$ ), hold a heritage view (high or low) of the coral reef and value the protection of the coral reef more than the marine/beach-

Table 9

Social acceptability gradient.

\begin{tabular}{llrr}
\hline & Sample & $\%$ \\
\hline In favour & High heritage view of the MPA & 177 & 44 \\
& Low heritage view of the MPA & 99 & 24 \\
Notional vision of the MPA & 42 & 10 \\
Undecided & 39 & 10 \\
Opposed & 3 & 1 \\
No opinion & 38 & 9 \\
No answer & 8 & 2 \\
Total & 406 & 100 \\
\hline
\end{tabular}


Table 10

Social acceptability based on values awarded to protection of the coral reef ecosystem and values awarded to the use of the resource.

\begin{tabular}{|c|c|}
\hline Values awarded to protection of the coral reef ecosystem & Social acceptability graduation \\
\hline Heritage value $>$ Use value & High social acceptability \\
\hline Heritage value $=$ Use value & Medium social acceptability \\
\hline Heritage value $<$ Use value & Low social acceptability a "face-value" social acceptability \\
\hline Heritage value $=0<$ Medium Use value & Non social acceptability \\
\hline Heritage value $=0<$ High Use value & High non social acceptability to overt action \\
\hline Heritage value $=0$ Use value $=0$ & No opinion on the MPA \\
\hline
\end{tabular}

related activities they participate in. A small proportion (13\%, $n=42$ ) of the MPA supporters possess a notional view of the MPA and do not approve of penalties being imposed for non-compliant behaviour.

\section{Discussion and conclusions}

Social acceptability constitutes a key factor for the sustainability of an MPA in Reunion Island as well as elsewhere. Overall, results from the survey used in this paper suggested a relatively high acceptance level of the MPA. However, although high levels of support were found in this study (as in similar studies [18]) this cannot be taken to be representative of the whole island as individuals that oppose the project may not have been reached by this survey. Even if in a minority, the views of opponents are likely to be stronger that those who support the MPA, particularly if new regulations will be costly to them [18]. Respondents said to be "undecided" towards the project may be the result of misunderstandings or disagreement with a particular aspects and may develop into opposition if not resolved. The MPA in Reunion, has been highly controversial and received fervent opposition in the past, resulting in fishermen blocking the main roads. The surveys used for this analysis were conducted in May 2006, nine months before the MPA was officially implemented. This period of the study was socially calm, like periods of transition between the negotiation phases (1997-2003) or the implementation phase (2007). During the negotiation phase, meetings and discussions were tense and decisions were often badly received, particularly by direct resource users such as fishermen. To demonstrate their discontent, roads and ports were blocked. Local media broadcasts and public opinion would have probably been more contrasted during these periods. Following the official declaration of the MPA in 2007 and its implementation, opposition has re-surfaced.

Focusing on school children's parents, the approach used presents a simple and cost-effective method for data collection while providing environmental education. Building on the binary mode (acceptance or refusal) in which social acceptability is sometimes limited, the approach used compares the value awarded by the public to the coral reef conservation with the value awarded to using the resource for marine/beach-related activities. The variation in the scale of opinion for those that support the MPA was summarised into three forms, based on their approval of the use of penalties on non-compliant users, as described below:

a) The approval for imposing maximum penalty fees was interpreted as a strong willingness to protect the coral reef ecosystem. This willingness was further interpreted as the basis for a high heritage value resulting from the association of an existence value, option value and bequest value.

b) The approval for imposing a minimum penalty fee was interpreted as a willingness to maintain existing uses and to protect the resource but without compromising use values. The heritage value is counterbalanced by the use value awarded to the resource. c) The disapproval of penalty fees being applied at all was interpreted as a willingness to maintain existing uses above all with the protection of the resource considered to be secondary to the use value derived from the resource. In this case, social acceptability can be considered to be minimal and the favourable response expressed in the questionnaire towards the MPA, can be disregarded as this does not seem to be based on any heritage value linked to the protection of the resource (Table 10).

Perceptions towards a coastal resource and its management can have a strong influence on public support and its success [21]. Recent research has revealed that the perceptions individuals hold of resource health and resilience is important in influencing environmentally-conscious behaviour [30,49] and perhaps more so than the environmental knowledge they possess [13,30]. If this is the case, the perceptions that people act upon can have direct consequences on environmental quality irrespective of whether they are 'accurate' in reality or not [50]. Such perceptions have been found to be influenced by a range of socio-economic factors such as wealth, age, education, culture, employment [34-37,51] or culturally defined 'worldview' they hold [30,52]. Socio-economic factors structure differences between and within communities particularly in developing societies and result in variations in the levels of understanding and acceptance of conservation projects [22,34,53]. Thus, identifying the factors that drive differing perceptions held by distinct social groups should be a key management objective as they can offer a valuable understanding of issues, concerns and reasons behind negative perceptions. Managers may then target groups to address concerns or knowledge gaps and thus encourage more positive perceptions to develop [19,22,53,54].

Those found to be supportive of the MPA in this study were generally from higher socio-professional categories, had a negative perception of the coral reef ecosystem's health and were not originally from Reunion. In contrast, locals (born in Reunion) from lower socio-professional categories or with no employment activity and having a positive perception of the health status of coral reefs offered no opinion on the MPA. Many were unaware of the future MPA or current Marine Park. Place of origin and employment level were found to be more important than location of residence in influencing social acceptability. However, socio-economic factors seem to be fundamentally tied to place of residence on Reunion Island [55].

In addition to employment and origin, perception of the coral reef ecosystem's health status was one of the main contributing factors to acceptability of the MPA. The support for enforcing regulations may also depend on how people perceive degradation. Fatalistic beliefs, that humans cannot harm the large scale marine processes, or the detachment of modern society from nature, contribute to a feeling that individuals and local actions cannot influence the global system they belong to [56]. Interestingly, answers concerning the overall state of the ecosystem were relatively well spread between those with positive and negative perceptions of it. However, fish abundance and submarine aesthetic appearance were generally perceived to be declining. At the same 
time, more than a third of respondents admitted that they never looked underwater or did not have any opinion on this. It is possible that direct contact with the marine environment and awareness of it is lacking in part of the population which may explain the relatively equal answers concerning overall state of the ecosystem. Similarly to employment and origin, perceptions held by residents of Reunion Island of coral resources state of health are strongly influenced and linked to where they live [55]. Awareness level of marine resources and its management also varies between locations [55]. So, while proximity to the resource was not found to affect acceptability, where people live does affect social acceptability because of the particular socio-cultural context. For example, the West Coast (closest to the MPA) is the most expensive residential area in contrast to the South and West Highlands.

Costs of enforcement through policing can be high if the public is unsympathetic to the objectives of a project such as an MPA and they may consequently disregard regulations [18]. When acceptability is high, an MPA manager can spend more time on conservation activities. At the same time, dealing with non-compliant behaviours such as poaching can be achieved more successfully when the objectives of the MPA are supported by the public. If social acceptability declines significantly, the legitimacy of an MPA manager to regulate and control access to natural resources may be challenged. Increased poaching may follow, resulting in a significant shift in the proportion of the MPA managers time spent on dealing with conflicts related to the rejection of the MPA. Many MPA managers' have marine biology or fisheries management qualifications and are poorly equipped to deal with people and manage conflicts. The prediction and prevention of conflicts is therefore crucial and social acceptability should be incorporated into all MPA management and assessment plans.

Attitudes towards enforcement and compliance highlighted that SCUBA divers, fishers and jet skiers attributed a higher value to protection of the coral reef through enforcement of MPA regulations than to their own use of the coral reef resource. When asked about the use of penalties to deter non-compliance swimmers were awarded the lowest fines, followed by SCUBA divers, fishers then jet skiers being awarded the highest fines. Thus, the more severe the act of non-compliance by a resource user group was perceived to be, the more these users themselves disapproved of non-compliant behaviour and supported use of high penalties. Studies have shown that people tend to under-estimate impacts of what is familiar to them [36] which may contribute to a greater tolerance of swimmers as this is the most popular and common activity.

Present regulations in Reunion have been badly enforced partly due to the low number of the Marine Guards, the absence of means for performing an arrest and lack of will from police force [55]. Behavioural theories suggest that individuals have little to gain from complying with regulations if others cheat the system [49]. If people believe that non-cooperation will result in collective demise it may be more rational for individuals to forgo benefits particularly if they understand that this will result in economic gains. This is particularly relevant where resources are limited as in Reunion. A related study in Reunion showed that many residents articulated concerns that other resource users in would not comply with regulations of the MPA [55]. It is therefore important that sufficient means are invested into the enforcement of the new MPA regulations.

Specific resource users such as divers, fishermen and tourists often hold different perceptions, attitudes and values to each other and the general public. As well as socio-economic differences between these groups, their perceptions are distinctly formed due to diverging motivation and interests in the resource $[18,56]$. Studying these resource user groups is crucial because of the direct effect management has on their activity and the specialist knowledge they are likely to have on the resource and its history. However, resident or public perceptions may in some cases be equally as relevant as they are influenced by a wider range of issues that include socio-economic factors and resource users interests reflecting the current 'feeling' of a society or community [53]. Their attitudes may be equal, if not more powerful in determining MPA success, as their perception of socially acceptable or intolerable behaviour can affect the extent to which other citizens and resource users behave and comply with regulations [49]. Assessing support or opposition towards enforcement is a crucial particularly in the critical early MPA stages [16,18,57].

Estimating social acceptability of the public towards an MPA ahead of its implementation was the first stage in the long-term assessment and monitoring process. The second stage is currently ongoing and consists of assessing the social acceptability of specific resource users closely linked to the coral reef ecosystem including: professional or traditional fishermen; surfers, windsurfers and kite surfers; divers and diving clubs, spear fishermen; tourists and the tourism industry. This should enable a better understanding of differing perceptions of different user groups and an analysis of alternative options for various user groups, as well as any displacement of user groups because of the MPA. The third stage will consist of a second assessment of social acceptability in 2008, one year after the implementation of the MPA which will feed in to the monitoring and assessment programmes which should be carried out in 2012.

\section{Acknowledgements}

The authors would like to acknowledge with thanks to all schools that took part in this study and those that responded to the questionnaire. The authors also thank the Tropical Agricultural Association Fund award and Newcastle University (Tropical Coastal Management) for funding Miss C. White, towards her MSc research project and field work, the Regional Council of Reunion Island and the Regional Cooperation Fund (FCR) of the Reunion Island Prefecture for funding Miss A. Thomassin to attend WIOMSA Conference in Durban. Many thanks also to two anonymous reviewers for providing improvements to this paper and to Mr. J Sydney for his help with the final draft.

\section{References}

[1] Agardy T, Bridgewater P, Crosby MP, Day J, Dayton PK, Kenchington R, et al. Dangerous targets? unresolved issues and ideological clashes around marine protected areas. Aquatic Conservation: Marine and Freshwater Ecosystems 2003;13(4):353-67.

[2] Anon. Conservation and sustainable use of marine and coastal biological diversity. CBD CoP2. Jakarta, 6-17 November 1995, http://www.cbd.int/ decisions/?dec=II/10; 1995.

[3] World Parks Congress. Building a Global System of Marine and Coastal Protected Area Networks. Recommendation 5.22 (approved) of the World Parks Congress, Durban, South Africa; 2003.

[4] Spalding M, Ravilious C, Green EP. World atlas of coral reefs. University of California Press; 2001.

[5] Spalding M, Kelleher G, Boucher T, Fish L. How protected are coral reefs? Science 2006;314(5800):758.

[6] Mora C, Andrèfouët S, Costello MJ, Kranenburg C, Rollo A, Veron J, et al. Coral reefs and the global network of marine protected areas. Science 2006;312(5781):1750-1 [Wash. DC].

[7] Ricciardi A, Jameson SC, McManus E, Besancon C, Johnson T, Spalding M, et al. How protected are coral reefs? Science 2006;314(5800):757.

[8] Chape S, Harrison J, Spalding M, Lysenko I. Measuring the extent and effectiveness of protected areas as an indicator for meeting global biodiversity targets. Philosophical Transactions of the Royal Society B: Biological Sciences 2005;360(1454):443-55.

[9] Jones PJS. Marine protected area strategies: issues, divergences and the search for middle ground. Reviews in Fish Biology and Fisheries 2001;11(3):197-216.

[10] Bunce L, Gustavson K, Williams J, Miller M. The human side of reef management: a case study analysis of the socioeconomic framework of Montego Bay marine Park. Coral Reefs 1999;18(4):369-80. 
[11] Crosby MP, bu-Hilal A, Al-Homoud A, Erez J, Ortal R. Interactions among scientists, managers and the public in defining research priorities and management strategies for Marine and Coastal resources: is the Red Sea Marine Peace Park a new paradigm? Water, Air, and Soil Pollution 2000;123(1):581-94.

[12] Christie P, McCay BJ, Miller ML, Lowe C, White AT, Stoffle R, et al. Toward developing a complete understanding: a social science research agenda for marine protected areas. Fisheries (Bethesda) 2003;28(12):22-6.

[13] Mascia MB. The human dimension of coral reef marine protected areas: recent social science research and its policy implications. Conservation Biology 2003;17(2):630-2.

[14] Davis GE. Science and society: marine reserve design for the California Channel Islands. Conservation Biology 2005;19(6):1745-51.

[15] Sloan NA. History and application of the wilderness concept in marine conservation. Conservation Biology 2002;16(2):294-305.

[16] Debrot AO, Nagelkerken I. User perceptions on coastal resource state and management options in Curacao. Revista de Biología Tropical 2000;48(1):95-106.

[17] Petrosillo I, Zurlini G, Corlian ME, Zaccarelli N, Dadamo M. Tourist perception of recreational environment and management in a marine protected area. Landscape and Urban Planning 2007;79(1):29-37.

[18] Sant M. Environmental sustainability and the public: responses to a proposed marine reserve at Jervis Bay, New South Wales, Australia. Ocean and Coastal Management 1996:32(1):1-16.

[19] Shafer CS, Benzaken D. User perceptions about marine wilderness on Australia's great Barrier reef. Coastal Management 1996;26(2):79-91.

[20] Suman D, Shivlani M, Walter Milon J, Stakeholder Group. Perceptions of marine reserves in the Florida keys National marine sanctuary. Ocean and Coastal Management 1999;42(12):1019-40.

[21] Pelletier D, Garcia-Charton JA, Ferraris J, David G, Thebaud O, Letourneur Y, et al. Designing indicators for assessing the effects of marine protected areas on coral reef ecosystems: a multidisciplinary standpoint. Aquatic Living Resources 2005;18(1):15-33.

[22] Beger M, Harborne AR, Dacles TP, Solandt JL, Ledesma GL. A framework of lessons learned from community-based marine reserves and its effectiveness in guiding a new coastal management initiative in the Philippines. Environmental Management 2004;34(6):786-801.

[23] Robertson DP, Hull RB. Public ecology: an environmental science and policy for global society. Environmental Science and Policy 2003;6(5):399-410.

[24] Hergon E, Moutel G, Bellier L, Hervé C, Rouger P. Les facteurs de perception et d'acceptabilité du risque: un apport pour la représentation du risque transfusionnel. Transfusion clinque et biologique 2004;11:130-7.

[25] Slovic P. Public perception of risk. Journal of Environmental Health 1997;59(9):22-5.

[26] Sullivan R. Assessing the social acceptability of environmental risk: a public policy perspective. Australian Journal of Environmental Management 1998;5:72-80.

[27] Hansis R. The social acceptability of clearcutting in the Pacific North West. Human Organization 1995;54(1):95-101.

[28] Kakoyannis C, Shindler B, Stankey G. Understanding the social acceptability of natural resource decision making processes by using a knowledge base approach. General Technical Report. PNWGTR-518. Portland, Oregon: U.S. Department of Agriculture, Forest Service, Pacific Northwest Research Station; 2001.

[29] Stankey G. Defining the social acceptability of forest management practices and conditions: integrating science and social choice. General Technical Report. PNW-GTR-369. In: Brunson MW, Kruger LE, Tyler CB, Schroeder SA, editors. Defining social acceptability in ecosystem management: workshop proceedings. Portland, Oregon: U.S. Department of Agriculture, Forest Service, Pacific Northwest Research Station; 1996. p. 99-111.

[30] Alessa L, Bennett SM, Kliskey AD. Effects of knowledge, personal attribution and perception of ecosystem health on depreciative behaviors in the intertidal zone of Pacific Rim National Park and reserve. Journal of Environmental Management 2003;68(2):207-18.

[31] Faucheux S, Noël JF. In: Collin Armand, editor. Economie des ressources naturelles et de l'environnement. Paris: Coll. U Economie; 1995. p. 370.

[32] David G, Herrenschmidt JB, Mirault E, Thomassin A. Social and economic values of Pacific coral reefs, Nouméa, CRISP/IRDed; 2007. pp. 44

[33] Stead SM, Daw T, Graham NAJ, Gray TS, Polunin NVC, Robinson J, et al. Trends in climate change, coastal governance, coral reef ecology and socio-economic variation in the Seychelles. In: IMAREST, editor. World Maritime Technology Conference. London; 2006.
[34] Cinner JE, Pollnac RB. Poverty, perceptions and planning: why socioeconomics matter in the management of Mexican reefs. Ocean and Coastal Management 2004;47(9-10):479-93.

[35] McClanahan T, Davies J, Maina J. Factors influencing resource users and managers' perceptions towards marine protected area management in Kenya. Environmental Conservation 2005;32(1):42-9.

[36] Peterlin M, Kontic B, Kross BC. Public perception of environmental pressures within the Slovene coastal zone. Ocean and Coastal Management 2005;48(2):189-204.

[37] Saenz-Arroyo A, Roberts CM, Torre J, Cario-Olvera M, Enriquez-Andrade RR. Rapidly shifting environmental baselines among fishers of the Gulf of California. Proceedings: Biological Sciences 2005;272(1575):1957-62.

[38] Anon. MEDD (Ministère de l'écologie, du développement et de l'aménagement durables). Présentation du département de la Réunion; 2004.

[39] Anon. Population. Evolution et structure de la population. INSEE (Institut National de la Statistique et des Études Économiques); 2006.

[40] Letourneur Y, Durville P, Taquet M, Teissier E, Parmentier M, Quero JM, et al. An updated checklist of the marine fish fauna of Reunion Island, South Western Indian Ocean. Cybium 2004;28(3):199-216.

[41] Conand C. Marine ecology of La Reunion: an overview of recent research. AMBIO: A Journal of the Human Environment 2002;31(7):602-5.

[42] Chabanet P, Letourneur Y. Spatial pattern of size distribution of four fish species on reunion coral reef flats. Hydrobiologia 1995;300(1):299-308.

[43] Durville P, Bosc P, Galzin R, Conand C. Colonization of a fringing reef of Reunion Island by coral fish larvae. Oceanologica Acta 2002;25(1):23-30.

[44] Letourneur Y, Harmelin-Vivien ML, Galzin R. Impact of hurricane Firinga on fish community structure on fringing reefs of Reunion Island, SW Indian Ocean. Environmental Biology of Fishes 1993;37(2):109-20.

[45] Chazottes V, Le Campion-Alsumard T, Peyrot-Clausade M, Cuet P. The effects of eutrophication-related alterations to coral reef communities on agents and rates of bioerosion (Reunion Island, Indian Ocean). Coral Reefs 2002;21(4):375-90.

[46] Naim O. Seasonal responses of a fringing reef community to eutrophication (Reunion Island, Western Indian Ocean). Marine Ecology Progress Series 1993;99:137-51.

[47] Chabanet P, Dufour V, Galzin R. Disturbance impact on reef fish communities in Reunion Island (Indian Ocean). Journal of Experimental Marine Biology and Ecology 1995;188(1):29-48.

[48] David G, Mirault E. L'épuisement de la ressource récifale de la Réunion: confrontation des perceptions et régulation de l'activité halieutique. In: Chaussade J, Guillaume J, editors. Pêche et aquaculture, pour une exploitation durable des ressources vivantes de la mer et du littoral: ouvrage en l'honneur de J.P. Corlay. Presses Universitaires, Rennes. Espace et Territoires; 2006. p. $127-40$.

[49] Burke BE. Hardin revisited: a critical look at perception and the logic of the commons. Human Ecology 2001;29(4):449-76.

[50] Pendleton L, Martin N, Webster DG. Public perceptions of environmental quality: a survey study of Beach use and perceptions in Los Angeles County. Marine Pollution Bulletin 2001;42(11):1155-60.

[51] Rao KN. Local peoples' knowledge, aptitude and perceptions of planning and management issues in Nanda Devi Biosphere reserve, India. Environmental Management 2003;31(2):168-81.

[52] Baticados DB. Fishing cooperatives participation in managing nearshore resources: the case in Capiz, central Philippines. Fisheries Research 2004;67(1):81-91.

[53] Myatt-Bell LB, Scrimshaw MD, Lester JN, Potts JS. Public perception of managed realignment: Brancaster west Marsh, North Norfolk, UK. Marine Policy 2002;26(1):45-57.

[54] Tran KC, Euan J, Isla ML. Public perception of development issues: impact of water pollution on a small coastal community. Ocean and Coastal Management 2002;45(6):405-20.

[55] White CS. Evaluation of public awareness prior to Marine reserve implementation in Reunion Island. MSc Tropical Coastal management dissertation. Newcastle University: UK; 2006. pp. 21 [unpublished work].

[56] McClanahan TR, Maina J, Davies J. Perceptions of resource users and managers towards fisheries management options in Kenyan coral reefs. Fisheries Management and Ecology 2005;12(2):105-12.

[57] Brailovskaya T. Obstacles to protecting marine biodiversity through marine wilderness preservation: examples from the New England region. Conservation Biology 1998;12(6):1236-40. 